\title{
Polymorphisms at codons 56 and 174 of the prion-like protein gene (PRND) are not associated with sporadic Creutzfeldt-Jakob disease
}

Received: 20 December 2004 / Accepted: 31 March 2005/Published online: 3 June 2005

(C) The Japan Society of Human Genetics and Springer-Verlag 2005

\begin{abstract}
Association between sporadic Creutzfeldt-Jakob disease (CJD) and the prion-like protein gene $(P R N D)$ has been reported in the German population. To investigate whether the $P R N D$ polymorphisms are associated with an increased risk for developing sporadic CJD in the Korean population, we compared the genotype and allele frequencies of $P R N D$ polymorphisms in 110 sporadic CJD patients with those in 102 healthy Koreans. Two polymorphisms (P56L, T174 M) in Koreans were found in the open reading frame (ORF) of $P R N D$. One heterozygote of P56L was observed in normal controls but not in sporadic CJD patients. A strong significant difference of $P R N D$ genotype frequency at codon 174 was found between the normal Korean population and various European populations. In contrast to results in the German population, our study did not show a significant difference in $P R N D$ genotype or allele frequency at codon 174 between sporadic CJD and normal controls. This was the first genetic association study of the ORF of PRND in an Asian CJD population.
\end{abstract}

Keywords Prion-like protein gene $\cdot$ Single nucleotide polymorphism - Doppel · Creutzfeldt-Jakob disease · Population genetics $\cdot$ Korean

\section{Introduction}

Human prion diseases are neurodegenerative disorders characterized by the accumulation of an abnormal

B.-H. Jeong · N.-H. Kim · Y.-S. Kim ( $₫)$

Ilsong Institute of Life Science, Hallym University,

Ilsong Building, 1605-4 Gwanyang-dong, Dongan-gu,

Anyang, Kyounggi-do, 431-060, South Korea

E-mail: yskim@hallym.ac.kr

Tel.: + 82-31-3801986

Fax: $+82-31-3883427$

J.-I. Kim · R. I. Carp

New York State Institute for Basic Research in Developmental Disabilities, Staten Island, NY 10314, USA protease-resistant isoform of the prion protein $\operatorname{PrP}^{\mathrm{Sc}}$ (Prusiner 1996). The prion-like protein gene (PRNP) plays an important role in conferring susceptibility to prion disease. A number of point and insert mutations of the PRNP have been linked to familial CreutzfeldtJakob disease (CJD), Gerstmann-Straussler-Scheinker disease (GSS), and fatal familial insomnia (FFI) (McKintosh et al. 2003). Morever, polymorphisms of PRNP appear able to influence expression of prion disease in sporadic and iatrogenic CJD (Collinge et al. 1991; Palmer et al. 1991; Shibuya et al. 1998).

The term Doppel $(\mathrm{Dpl})$ is derived from downstream prion protein-like gene. The PrP-like protein gene $(P R N D)$ is located $27 \mathrm{~kb}$ downstream of the human $P R N P$. Its open reading frame (ORF) has been shown to contain polymorphic codons, but studies on a correlation between the $P R N D$ polymorphisms and neurodegenerative disorders in various populations have shown contradictory results (Peoc'h et al. 2000; Mead et al. 2000; Schroder et al. 2001; Infante et al. 2002; Croes et al. 2004; Golanska et al. 2004). Therefore, the role of the $P R N D$ in CJD and other diseases still remains unexplained. The major $P R N D$ polymorphism in these studies was substitution from threonine (Thr) to methionine (Met) at codon $174(\mathrm{~T} 174 \mathrm{M})$. This polymorphism in British, French, and Dutch populations was not associated with sporadic CJD or variant CJD (Peoc'h et al. 2000; Mead et al. 2000; Croes et al. 2004). In the Spanish population, the polymorphism was not associated with sporadic Alzheimer's disease (AD) (Infante et al. 2002). In contrast with these studies, this polymorphism in German populations was associated with sporadic CJD and/or AD (Schroder et al. 2001). Other polymorphisms were observed at codons 26 (T26 M) and 56 (P56L) (Mead et al. 2000; Peoc'h et al. 2000; Schroder et al. 2001; Infante et al. 2002). These polymorphisms were not associated with susceptibility to sporadic CJD (Mead et al. 2000; Peoc'h et al. 2000). The genotype frequencies of $P R N P$ polymorphisms in Asian populations, including Koreans, are considerably different from those in Europeans (Palmer et al. 1991; 
Jeong et al. 2004). Although the polymorphisms of the $P R N D$ have been studied in several European countries (Mead et al. 2000; Peoc'h et al. 2000; Schroder et al. 2001; Infante et al. 2002; Croes et al. 2004; Golanska et al. 2004), there have been no reports of $P R N D$ from other parts of the world.

The purpose of this study was to examine the genotype frequencies of $P R N D$ polymorphisms in Koreans and to investigate whether the polymorphisms of the $P R N D$ can be associated with sporadic CJD in a Korean population.

\section{Materials and methods}

\section{CJD patient population}

We used previously established criteria (Zerr et al. 2000) for diagnosis of sporadic CJD in Korea. Neuropathologically confirmed patients and/or patients with immunochemical detection of $\mathrm{PrP}^{\mathrm{Sc}}$ in the brain were classified as definite CJD. Patients were classified as probable CJD if they exhibited a rapidly progressive dementia, periodical sharp wave complexes (PSWC) on electroencephalography (EEG), 14-3-3 protein in CSF, a duration of dementia $<2$ years, and two of the following: myoclonus, visual and cerebellar symptoms or both, pyramidal and extrapyramidal signs or both, or akinetic mutism. Those fulfilling the above clinical criteria and the duration of $<2$ years but without PSWC and 14-3-3 detection in CSF were classified as possible CJD. The sporadic CJD cases, which were diagnosed by immunohistochemistry and DNA sequencing, have been reported previously (Jeong et al. 1998). To provide a reliable assessment of CJD in Korea, we carried out molecular experiments, including Western blots as well as immunohistochemistry. Of the 188 suspected CJD cases, 17 were classified as definite CJD, and 93 were classified as probable CJD.

\section{Blood samples}

Blood samples were collected from 102 healthy Korean volunteers and 110 sporadic CJD patients, which were collected between May 1996 and October 2004. The study was approved by the ethical committee of Chunchon Sacred Heart Hospital, and all volunteers and sporadic CJD patients gave informed consent. All blood samples were frozen at $-70^{\circ} \mathrm{C}$ prior to analysis.

\section{Polymerase chain reaction}

Genomic DNA was extracted from $200 \mu$ l blood using the QIAamp DNA blood mini kit (Qiagen, USA) following the supplier's instructions. Polymerase chain reaction (PCR) was performed with Hdpl-1 (5'GTTTCTCTGGCAGGTTCTG-3') and Hdpl-2 (5'GAGAAGAGCTGGGTCACTT-3') primers. These primers were designed to amplify a 623-bp product, including the complete human Dpl ORF (528-bp) and adjacent sequences. The PCR reagents contained 50 pmol of each primer, $5 \mu$ of ten times Taq DNA polymerase buffer, $1.5 \mathrm{mM} \mathrm{MgCl} 2,0.2 \mathrm{mM}$ of each dNTP mixture, and 2.5 units of Taq DNA polymerase (Promega, USA). The PCR conditions were as follows: an initial denaturation step of $95^{\circ} \mathrm{C}$ for $2 \mathrm{~min}, 30$ cycles of $94^{\circ} \mathrm{C}$ for $40 \mathrm{~s}, 56^{\circ} \mathrm{C}$ for $45 \mathrm{~s}, 72^{\circ} \mathrm{C}$ for $90 \mathrm{~s}$, and final extension at $72^{\circ} \mathrm{C}$ for $10 \mathrm{~min}$.

\section{Nucleotide sequencing analysis}

The purification of PCR products for sequencing was done using a QIA quick gel extraction kit (Qiagen, USA). The PCR products were directly sequenced on an ABI 377 automatic DNA sequencer using a Taq dideoxy terminator cycle sequencing kit (ABI, USA) and the same primers as above in standard conditions. Nucleic acid sequences were assembled, and edited was done using a combination of the ABI 377 DNA Sequencer Data Analysis Program and Sequence Navigator Software.

\section{Statistical analysis}

Statistical analysis was performed using the SAS 8.1 Software (SAS Institute Inc., USA). Differences in genotype frequencies between healthy Koreans and patients with sporadic CJD were analyzed by $\chi^{2}$ tests.

\section{Results}

Direct sequencing of the PCR products of the $P R N D$ amplified in 102 Korean normal individuals and 110 sporadic CJD patients identified two SNPs in the ORF of the gene. The minor $P R N D$ polymorphism found in the Korean population was P56L (Table 1). No significant difference was found in genotype distribution or allele frequency between sporadic CJD and the normal population at this codon. Furthermore, this polymorphism, examined in France, Britain, and Korea, was not associated with susceptibility to sporadic CJD. The major PRND polymorphism was T174 M (Table 1). The frequency of the T174 allele in the normal Korean population is slightly higher than that in the German population and substantially greater than French, British, and Dutch populations. In order to examine correlation between this polymorphism and susceptibility of sporadic CJD in Koreans, we also analyzed the genotype and allele frequencies in 110 sporadic CJD cases. No significant difference was found between sporadic CJD and normal controls in genotype distribution or allele frequency. Furthermore, neither was there any association between age at onset or duration of disease in sporadic CJD and genotype (Table 2). Also, there was no significant association 
Table 1 Genotype and allele frequencies of the polymorphisms at codons 56 and 174 of the prion-like protein gene $(P R N D)$ in normal population and sporadic Creutzfeldt-Jakob disease (CJD) patients from France, Britain, Germany, Holland, and Korea

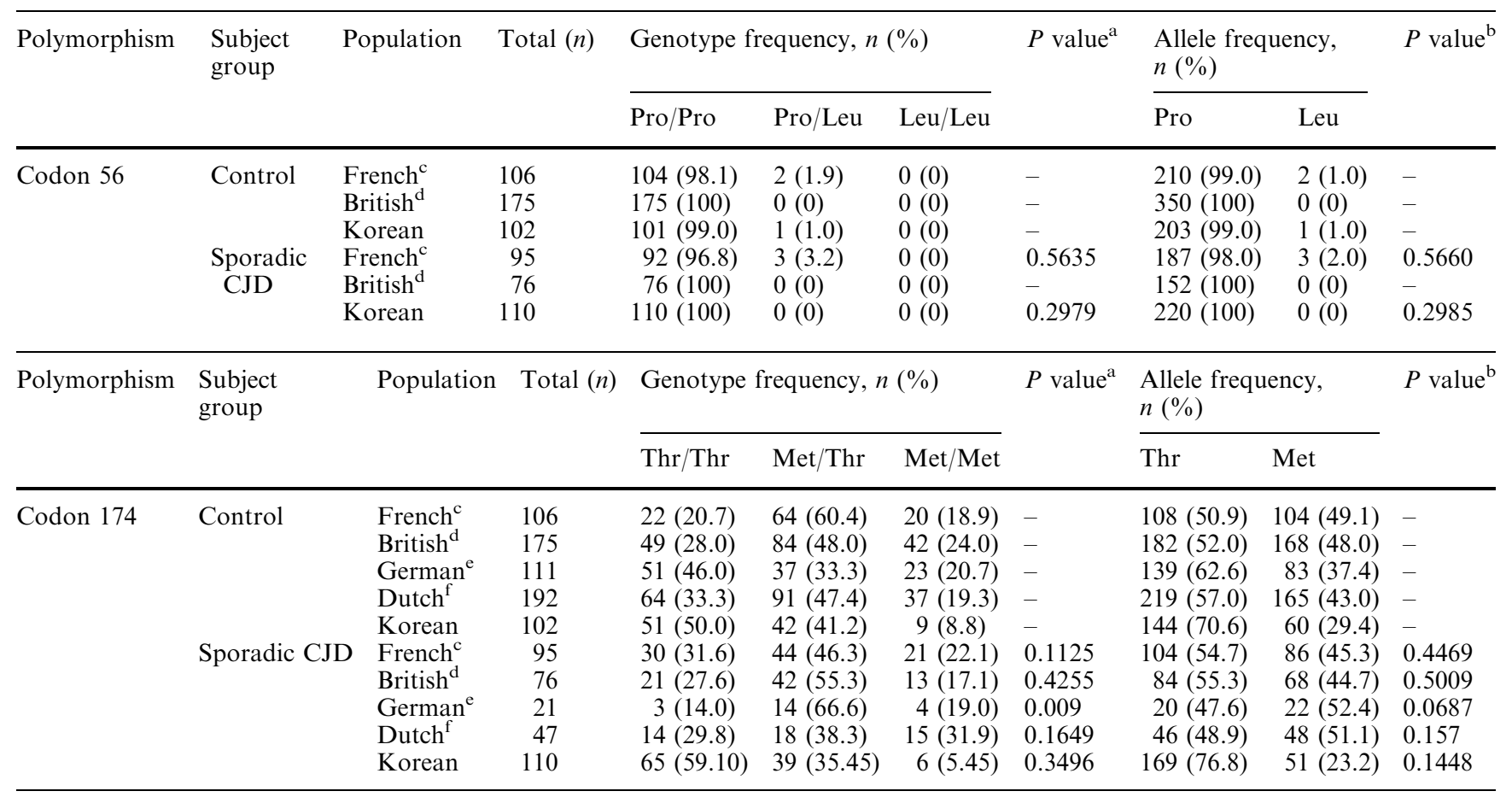

\footnotetext{
a Based on comparison of genotype frequencies between controls and sporadic CJD patients

${ }^{\mathrm{b}}$ Based on comparison of allele frequencies between controls and sporadic CJD patients

${ }^{\mathrm{c}}$ Peoc'h et al. (2000)

d Mead et al. (2000)

e Schroder et al. (2001)

${ }^{f}$ Croes et al. (2004)
}

Table 2 Genotypes at codon 174 of the prion-like protein gene $(P R N D)$, age of onset, duration of illness, and PrP $\mathrm{P}^{\mathrm{Sc}}$ type in Korean normal population and sporadic Creutzfeldt-Jakob disease (CJD) patients

\begin{tabular}{|c|c|c|c|c|c|}
\hline & \multirow[t]{2}{*}{ Total $(n)$} & \multicolumn{3}{|c|}{ Genotype frequency, $n(\%)$} & \multirow[t]{2}{*}{$P$ value $^{\mathrm{a}}$} \\
\hline & & $\mathrm{Thr} / \mathrm{Thr}$ & Met/Thr & Met/Met & \\
\hline Sporadic CJD patients & 110 & $65(59.10)$ & $39(35.45)$ & $6(5.45)$ & 0.3496 \\
\hline Definite cases & 17 & $10(58.8)$ & $6(35.3)$ & $1(5.9)$ & 0.7802 \\
\hline Age of onset (mean \pm SEM) (years) & $16 / 17$ & $58.6 \pm 11.0$ & $57.6 \pm 3.1$ & 58.0 & \\
\hline $\begin{array}{l}\text { Duration of illness (mean } \pm \text { SEM) (months) } \\
\operatorname{PrP}^{\mathrm{Sc}} \text { type }\end{array}$ & $10 / 17$ & $5.83 \pm 2.3$ & $5.7 \pm 0.6$ & 5.2 & \\
\hline Probable cases & 93 & $55(59.1)$ & $33(35.5)$ & $5(5.4)$ & 0.3748 \\
\hline Age of onset (mean \pm SEM) $\quad$ (years) & $93 / 93$ & $62.4 \pm 11.4$ & $65.6 \pm 11.4$ & $60.2 \pm 14.6$ & \\
\hline Duration of illness (mean \pm SEM) (months) & $46 / 93$ & $5.6 \pm 2.5$ & $5.8 \pm 2.7$ & $5.0 \pm 1.7$ & \\
\hline
\end{tabular}

${ }^{a}$ Based on comparison of genotype frequencies between controls and sporadic CJD patients

between $\mathrm{PrP}^{\mathrm{Sc}}$ type and this polymorphism. These results suggest that the T174 M polymorphism does not increase susceptibility to sporadic CJD.

In addition, we looked for the presence of T26 M $P R N D$ polymorphism and elsewhere in the ORF of the $P R N D$, but we found none in our sampling of the Korean population.

\section{Discussion}

In this study, we studied polymorphisms at codons 56 and 174 of the ORF of $P R N D$ in a sampling of the Korean population. We have not found evidence that polymorphisms of the ORF of $P R N D$ are associated 
with susceptibility to sporadic CJD. To our knowledge, ours is the first genetic association study of the ORF of $P R N D$ with CJD in an Asian population.

In previous studies, the P56L PRND polymorphism has been reported in the French population but not in the British population (Mead et al. 2000; Peoc'h et al. 2000). In the French population, the distributions of $P R N D$ genotype and allele frequencies in sporadic CJD patients did not significantly differ from those of controls. The genotype frequency of the T174 M PRND polymorphism in the normal Korean population differs significantly from that previously reported for the British $\left(\chi^{2}=17.3604, P=0.0002\right)$, French $\left(\chi^{2}=20.1895\right.$, $P<0.0001)$, German $\left(\chi^{2}=6.072, P=0.048\right)$, and Dutch populations $\left(\chi^{2}=9.947, P=0.007\right)(\mathrm{Mead}$ et al. 2000; Peoc'h et al. 2000; Schroder et al. 2001; Croes et al. 2004). These results suggest that there is a difference in the genotype frequency of this polymorphism between Europeans and Asians. In Koreans, neither the genotype nor allele frequency of the T174 M PRND polymorphism is associated with sporadic CJD. This result supports the British, French, and Dutch findings but not the German data. We have not found evidence that polymorphisms in ORF of the $P R N D$ are associated with susceptibility to sporadic CJD. Also, there were no significant differences in genotype frequencies between definite sporadic CJD or probable sporadic CJD and controls, even after stratifying by onset of age, duration of disease, and $\mathrm{PrP}^{\mathrm{Sc}}$ type (Table 2). The positive results in the German population may have arisen by chance due to the very small sample size of sporadic CJD patients studied (21 cases) (Schroder et al. 2001).

Acknowledgements We thank Drs. Cheyong Lee and Yong-Hee Kim for help with the statistical analysis. This work was supported by the Korea Food and Drug Administration Grant.

\section{References}

Collinge J, Palmer MS, Dryden AJ (1991) Genetic predisposition to iatrogenic Creutzfeldt-Jakob disease. Lancet 337:14411442
Croes EA, Alizadeh BZ, Bertoli-Avella AM, Rademaker T, Vergeer-Drop J, Dermaut B, Houwing-Duistermaat JJ, Wientjens DP, Hofman A, Van Broeckhoven C, van Duijn CM (2004) Polymorphisms in the prion protein gene and in the doppel gene increase susceptibility for Creutzfeldt-Jakob disease. Eur J Hum Genet 12:389-394

Golanska E, Hulas-Bigoszewska K, Rutkiewicz E, Styczynska M, Peplonska B, Barcikowska M, Bratosiewicz-Wasik J, Liberski PP (2004) Polymorphisms within the prion (PrP) and prion-like protein (Doppel) genes in AD. Neurology 62:313-315

Infante J, Llorca J, Rodero L, Palacio E, Berciano J, Combarros O (2002) Polymorphism at codon 174 of the prion-like protein gene is not associated with sporadic Alzheimer's disease. Neurosci Lett 332:213-215

Jeong BH, Ju WK, Huh K, Lee EA, Choi IS, Im JH, Choi EK, Kim YS (1998) Molecular analysis of prion protein gene (PRNP) in Korean patients with Creutzfeldt-Jakob disease. J Kor Med Sci 13:234-240

Jeong BH, Nam JH, Lee YJ, Lee KH, Jang MK, Carp RI, Lee HD, Ju YR, Jo SA, Park KY, Kim YS (2004) Polymorphisms of the prion protein gene (PRNP) in a Korean population. J Hum Genet 49:319-324

Mckintosh E, Tabrizi SJ, Collinge J (2003) Prion diseases. J Neurovirol 9:183-193

Mead S, Beck J, Dickinson A, Fisher EM, Collinge J (2000) Examination of the human prion protein-like gene doppel for genetic susceptibility to sporadic and variant Creutzfeldt-Jakob disease. Neurosci Lett 290:117-120

Palmer MS, Dryden AJ, Hughes JT, Collinge J (1991) Homozygous prion protein genotype predisposes to sporadic Creutzfeldt-Jakob disease. Nature 352:340-342

Peoc'h K, Guerin C, Brandel JP, Launay JM, Laplanche JL (2000) First report of polymorphisms in the prion-like protein gene (PRND): implications for human prion diseases. Neurosci Lett 286:144-148

Prusiner SB (1996) Introduction: prion diseases. Sem Virol 7:157173

Schroder B, Franz B, Hempfling P, Selbert M, Jurgens T, Kretzschmar HA, Bodemer M, Poser S, Zerr I (2001) Polymorphisms within the prion-like protein gene (Prnd) and their implications in human prion diseases, Alzheimer's disease and other neurological disorders. Hum Genet 109:319-325

Shibuya S, Higuchi J, Shin RW, Tateishi J, Kitamoto T (1998) Codon 219 Lys allele of PRNP is not found in sporadic Creutzfeldt-Jakob disease. Ann Neurol 43:826-828

Zerr I, Pocchiari M, Collins S, Brandel JP, de Pedro Cuesta J, Knight RS, Bernheimer H, Cardone F, Delasnerie-Laupretre N, Cuadrado Corrales N, Ladogana A, Bodemer M, Fletcher A, Awan T, Ruiz Bremon A, Budka H, Laplanche JL, Will RG, Poser S (2000) Analysis of EEG and CSF 14-3-3 proteins as aids to the diagnosis of Creutzfeldt-Jakob disease. Neurology $55: 811-815$ 